\title{
Lateral Knee Osteoarthritis
}

\section{Alejandro Alvarez López}

Department of Orthopaedic Surgery. Full profesor. University Hospital Manuel Ascunce Domenech. Camagüey City. Cuba.

Corresponding Author: Alejandro Alvarez López, Department of Orthopaedic Surgery. Full profesor. University Hospital Manuel Ascunce Domenech. Camagüey City. Cuba.

Received Date: November 01, 2021; Accepted Date: December 20, 2021; Published Date: January 03,2022

Citation: Alejandro Alvarez López (2022). Lateral Knee Osteoarthritis. J. Clinical Orthopedics and Trauma Care, 4(1); Doi:10.31579/26940248/017

Copyright: (C) 2022 Alejandro Alvarez López, This is an open-access article distributed under the terms of the Creative Commons Attribution License, which permits unrestricted use, distribution, and reproduction in any medium, provided the original author and source are credited.

Abstract

Background: gonarthrosis is a common entity characterized by involvement of one or more compartments, of which the lateral one is the one with the lowest incidence in isolation.

Aim: the aims of this research are too updated on the most important features on lateral knee osteoarthritis and look for updated bibliography on the subject.

Methods: PubMed, Hinari, SciELO and Medline databases were searched for citations from August $1^{\text {st }} 2021$ to September $30^{\text {th }} 2021$ using the EndNote search manager and reference manager. Out of 312 articles, 44 selected citations were used in this review, being 42 of the last five years.

Results: the main causes of lateral knee osteoarthritis are mentioned, especially the secondary ones. Reference is made to the main clinical and imaging elements for diagnosis based on plain radiography and magnetic resonance imaging. Both conservative and surgical treatment modalities are exposed, in the latter the main indications and complications are described, among which osteotomies and arthroplasties stand out.

Conclusions: lateral gonarthrosis is the least common of the unicompartmental gonarthrosis that affect the knee joint. Clinical and imaging diagnosis provides the essential elements for both conservative and surgical therapeutic behaviour, the latter modality includes techniques that preserve the joint such as osteotomies and others that do not, such as arthroplasties.

Key words: lateral knee osteoarthritis; valgus angular deviation; arthroscopy; osteotomy; partial and total knee replacement

\section{Introduction}

Osteoarthritis is the most common degenerative and progressive joint disease. It affects millions of people and involves joints such as the hips, spine and knees with a high economic cost.

The knee is one of the most affected joints by this degenerative entity, the main symptoms and signs are mechanical pain with swelling and limitation of joint movement to different degrees, accompanied by crepitus and locking. [1, 2]

A simple X-ray is the most used test to confirm the diagnosis; it stands out due to its low cost and high availability. Radiographs may show the classic signs of joint space narrowing, sclerosis, subchondral cysts, osteophytes and subluxation. $[3,4]$

The knee joint is made up of three compartments, the medial and lateral tibiofemoral, in addition to the patellofemoral; all of them are not affected symmetrically. Unicompartmental knee osteoarthritis, mostly affects the medial tibiofemoral compartment, then the patellofemoral and finally the lateral one with the lowest incidence of all. Valgus deviation is defined as one that exceeds 7 to 10 degrees. [5, 6, 7]
Treatment of patients with lateral gonarthrosis ranges from conservative to surgical modalities, the latter differentiated between those that preserve the joint and others that do not, such as partial or total arthroplasties, each modality with very specific indications. [8, 9, 10]

The aims of this investigation are too updated on the most important features of lateral knee osteoarthritis and look for updated bibliography on the subject.

\section{Methods}

An extensive literature search in various data bases such as: PubMed [https://pubmed.ncbi.nlm.nih.gov/],

Hinari

[https://www.who.int/hinari/es/], SciELo [https://scielo.org/es/] and Medline [https://medlineplus.gov] was carried out with search term including ' lateral knee osteoarthritis', 'valgus knee osteoarthritis', and 'valgus knee deformity' from August 1st 2021 to September 30th 2021. Out of 312 articles, 44 selected citations were used in this review, being 42 of the last five years. 
Our inclusion criteria included all the investigations in patients with lateral knee osteoarthritis. Articles related to complications derived from arthroplasty and those carried out in immature skeletons were excluded.

\section{Etiology}

Lateral knee osteoarthritis may be primary or secondary, within the latter, the post-traumatic gonarthrosis is due to previous fractures of the tibial plateau and postoperative procedures such as meniscectomies. Lateral tibial plateau is more convex than medial that is why meniscectomy increases significantly the contact between the joint surfaces and favors the development of degenerative changes in the joint. $[11,12]$

\section{Pertinent physical examination and imaging}

Patients with lateral knee osteoarthritis usually seek medical assistance complaining of moderate to severe pain and valgus deformity; both have been increased in recent months accompanied by gait claudication. On physical examination, the valgus deformity is detected by inspection; a simple and effective method of detecting angulation is by measuring the $\mathrm{Q}$ angle, from the anterior superior iliac spine to the center of the patella and from there to the anterior tibial tuberosity (Figure 1). [13, 14]

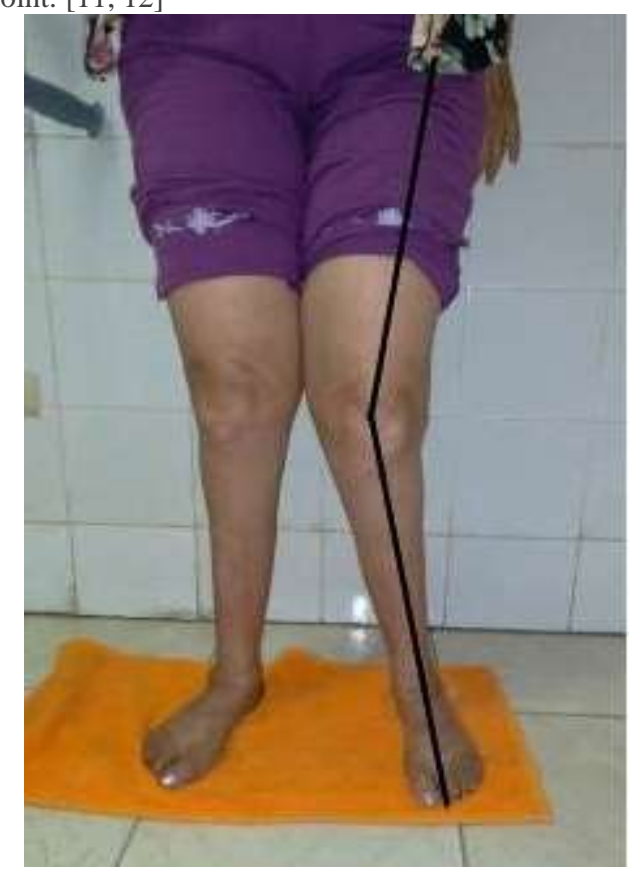

Figure 1. Patients with lateral knee osteoarthritis and valgus deformity.

On palpation, joint line pain or well-localized pain, crepitus, effusion, locking and catching can be detected. Stability maneuvers show laxity of the medial ligaments and shortening of the lateral ones, these are essential elements to be taken into account for treatment. $[14,15]$

Radiography is of great help for the diagnosis, but it is important to remember that osteoarthritis is an entity in which the clinical and imaging features are not linear and symmetrical, hence there may be patients with marked degenerative changes on radiographs and have few symptoms or vice versa. On plain radiographs Fujisawa point should be calculated to determinate osteotomy and evaluate limb alignment after surgical procedures. [16, 17, 18]

Although the most widely used imaging tests are plain radiographies in posteroanterior and lateral weight-bearing projections with 30 degrees of knee flexion Rosenberg view), magnetic resonance imaging also provides highly helpful features, especially those related to the condition status of the menisci, thickness and contour of the articular cartilage in addition to the state of the rest of the compartments within the joint. [20, 21]

Computerized axial tomography has very specific indications in patients with lateral knee osteoarthritis and its use is reserved for evaluating bone anatomy in surgical planning. [22, 23]

Treatment methods for patients with lateral knee osteoarthritis are similar to those of the rest of the compartments; however patients tolerate nonoperative treatment better than those with medial compartment involvement. [24, 25]

\section{Treatment}

\subsection{Nonoperative treatment}

Nonoperative treatment is the most used modality and includes nonsteroidal anti-inflammatory analgesics, viscosupplementation, and intraarticular steroids. Others non-pharmacological treatment options such as braces or orthoses, modifications of footwear and physical activity, body weight lost, use of crutches or canes and physical therapy and rehabilitation also may be helpful. Pain relief from the use of orthoses suggests a good future response to corrective osteotomies and unicompartmental arthroplasties. [26, 27]

\subsection{Surgical treatment}

Surgical procedures for patients with lateral knee osteoarthritis and valgus deformity are osteotomies, and unicompartmental or total arthroplasty. The first modality respects the patient's joint and manages to correct the deformity. [28, 29]

Corrective osteotomies in patients with lateral knee osteoarthritis aim to reduce the weight load in the affected compartment. General indications for osteotomy include age (younger than 65 years), patients with degrees I and II of Ahlback classification of lateral compartment, slight laxity of the ligaments, and a good range of motion of at least 90 degrees of knee flexion. [30, 31]

Contraindications for femoral osteotomies are: the presence of osteoarthritis of the medial or tricompartmental compartment, symptoms 
related to the medial compartment of the joint due to inflammatory arthritis, flexion contracture greater than 15 degrees, knee flexion less than 90 degrees and severe osteoporosis. [32, 33]

Distal femoral osteotomies may be medial closed and lateral open, both with the purpose of aligning the limb and achieving a horizontal joint line placement. The differences between these two procedures can be seen in Table 1. [28, 31]

\begin{tabular}{|l|ll|}
\hline Factor & Medial & Lateral \\
\hline Technical difficulty & Greater & Less \\
\hline Need for graft & No & Yes \\
\hline Delayed union & Less & Greater \\
\hline Cut over the bone & Complete (both corticals) & Partial (one cortical) \\
\hline
\end{tabular}

Table 1: Differences between femoral osteotomies for patients with lateral knee osteoarthritis and valgus deformity.

Arthroscopy can be performed in conjunction with osteotomy and is justified in patients with the presence of symptoms and mechanical joint signs due to involvement of the menisci and the possibility of loose bodies. Arthroscopy allows the performance of meniscectomies, synovectomy, and removal of loose bodies and grading of the cartilage condition in each of the compartments. [2, 34]

Advantages and disadvantages of arthroscopy and osteotomy at the same tome are summarized in the table 2. [35, 36]

\begin{tabular}{|l|l|}
\hline Advantages & Disadvantages \\
\hline $\begin{array}{l}\text { Two surgical procedures (arthroscopy and osteotomy) are } \\
\text { performed at the same time. }\end{array}$ & Longer surgical time. \\
\hline $\begin{array}{l}\text { Weight bearing is not allowed after osteotomy and in case of } \\
\text { microfracture by arthroscopy, at one time. }\end{array}$ & A long learning curve is needed. \\
\hline It allows a real time evaluation of the articular surface. & \\
\hline The combined technique reduces time to star rehabilitation. & \\
\hline
\end{tabular}

Table 2: Advantages and disadvantages of arthroscopy and osteotomy at the same time.

Complications related to of osteotomy in patients with lateral knee osteoarthritis are few, the most common complication is joint stiffness, and its incidence is reduced by avoiding the joint during surgery. Nonunion is the second most common complication with an incidence of 4.2 to $19 \%$ and is associated with failure of the osteosynthesis material, especially when it is placed on the medial side. [32, 33]

Lateral unicompartmental arthroplasty represents from 10 to $23 \%$ of all partial arthroplasties, it is a surgical treatment modality that preserves part of the joint; the main indications for this treatment are isolated involvement of the lateral compartment with a 90-degree joint range of motion. The advantages of this technique lie in the low loss of blood during the operation and a low rate of complications. [37, 38]
The results of medial and lateral partial arthroplasty are similar. Partial arthroplasty is contraindicated in patients with involvement of other compartments of the knee, presence of instability, inflammatory arthritis, and fixed valgus deformity. In these situations, total joint arthroplasty is more advisable. [39, 40]

Lateral knee osteoarthritis usually appears later in life, hence total knee replacement is a very good option in these patients. The main indication for total knee arthroplasty is tricompartmental joint disease associated with limited response to pain despite nonoperative treatment and other surgical treatment modalities. [41, 42]

Krackow KA classification cited by Greenberg A et al. is useful during the performance of total knee arthroplasty in patients with valgus deformity and is divided into three grades (Table 3).

\begin{tabular}{|l|l|}
\hline Types & Characteristics \\
\hline I & Involves lateral femoral bone loss, lateral soft tissue contractures, and intact medial soft tissues. \\
\hline II & Adds lengthened medial soft tissues. \\
\hline III & Is a severe valgus deformity with malpositioning of the proximal tibial joint line? \\
\hline
\end{tabular}

Table 3: Krackow KA classification cited by Greenberg a et al., [43] for patients with valgus deformity during the placement of total knee arthroplasty.

Valgus contracture causes contracture of the lateral structures, hence the need for extensive releases to achieve alignment and balance of the ligaments, and for this reason patellofemoral instability and peroneal nerve injuries can occur. $[42,43]$

At present, robotic and navigational surgery significantly improve the short-term and long-term results of all the surgical modalities described above. [44]

\section{Conclusions}

Lateral knee osteoarthritis is the least common of the unicompartmental osteoarthritis that affect the knee joint. The clinical and imaging diagnosis provides the essential features for both nonoperative and surgical modalities, the latter modality includes techniques that preserve the joint such as osteotomies associated to arthroscopy and others that do not, among which arthroplasties stand out.

\section{Declaration of competing interest}

Nil grants/funding

The author declares no conflict of interest.

The material has not been previously presented.

\section{References}

1. Rosenthal PB. Knee osteoarthritis. In: Scott WN. Insall \& Scott Surgery of the Knee. 6 th ed. Philadelphia: Elsevier; 2018:992997. 
2. Bert JM. Arthroscopic treatment of degenerative arthritis of the knee. In: Johnson DJ. Operative Arthroscopy. 4 th ed. Philadelphia: Wolters Kluwer; 2013:746-753.

3. Han X, Cui J, Xie K, Jiang X, He Z, Du J, et al. Association between knee alignment, osteoarthritis disease severity, and subchondral trabecular bone microarchitecture

in patients with knee osteoarthritis: a cross-sectional study. Arthritis Res Ther 2020; 22:203.

4. Wang WJ, Sun MH, Palmer J, Liu F, Bottomley N, Jackson W, et al. Patterns of compartment involvement in end-stage knee osteoarthritis in a Chinese Orthopedic Center: implications for implant choice. Orthop Surg 2018; 10:227-234.

5. Ambra LF, Gomoll AH, Farr J. Coronal and axial alignment: the effects of malalignment. In: Yanke AB, Cole BJ. Joint preservation of the knee: a clinical casebook. Cham: Springer; 2019:41-56.

6. Encinas Ullán CA, Gómez Cardero P, Rodríguez Merchant EC. Unicompartimental knee osteoarthritis: alignment osteotomies. In: Rodríguez Merchant EC, Gómez Cardero P. Comprehensive treatment of knee osteoarthritis. Cham: Springer; 2020:63-75.

7. McAuliffe MJ, Garg G, Orschulok T, Roe J, Whitehouse SL, Crawford R. Coronal plane laxity of valgus osteoarthritic knee. J Orthop Surg (Hong Kong) 2019; 27.

8. Karas V, Berger RA. Lateral unicompartimental knee arthroplasty: indication and technique. In: Gerlinger TL. Unicompartimental knee arthroplasty: indications, surgical techniques and complications. Cham: Springer; 2020:95-105.

9. Palmer AJR, Price AJ. Osteotomies about the knee. In: Rodriguez Merchánt EC, Liddle $\mathrm{AD}$. Joint preservation in the adult knee. Cham: Springer; 2017:175-183.

10. Graef F, Hommel H, Falk R, Tsitsilonis S, Zahn RK, Perka C. Correction of severe valgus osteoarthritis by total knee arthroplasty is associated with increased postoperative ankle symptoms. Arthrosc 2020:24.

11. Klasan A, Putnis SE, Neri T, Leie M, Coolican MR. Patients with lateral compartment knee osteoarthritis during arthroscopy are at highest risk of subsequent knee arthroplasty. Knee 2020; 27:1476-1483.

12. Koga H, Nakamura T, Katagiri H, Nakagawa Y, Ozeki N, Ohara T, et al. Two-year outcomes after meniscoplasty by capsular advancement with the application of arthroscopic centralization technique for lateral compartment knee osteoarthritis. Am J Sports Med 2020; 48:3154-3162.

13. van Tunen JAC, Dell'Isola A, Juhl C, Dekker J, Steultjens M, Thorlund JB, Lund H. Association of malalignment, muscular dysfunction, proprioception, laxity and abnormal joint loading with tibiofemoral knee osteoarthritis - a systematic review and meta-analysis. BMC Musculoskelet Disord 2018; 19:273.

14. Thienpont E, Schwab PE, Cornu O, Bellemans J, Victor J. Bone morphotypes of the varus and valgus knee. Arch Orthop Trauma Surg 2017;137:393-400.

15. Faschingbauer M, Kasparek M, Waldstein W, Schadler P, Reichel H, Boettner F. Cartilage survival of the knee strongly depends on malalignment: a survival analysis from the Osteoarthritis Initiative (OAI). Knee Surg Sports Traumatol Arthrosc 2020; 28:1346-1355.

16. Wang B, Liu Q, Wise BL, Ke Y, Xing D, Xu Y, et al. Valgus malalignment and prevalence of lateral compartmental radiographic knee osteoarthritis (OA): The Wuchuan OA study. Int J Rheum Dis 2018; 21:1385-1390.

17. Parsons C, Fuggle NR, Edwards MH, Goulston L, Litwic AE, Jagannath D, et al. Concordance between clinical and radiographic evaluations of knee osteoarthritis. Aging Clin Exp Res 2018; 30:17-25.
18. Yin Y, Li S, Zhang R, Guo J, Hou Z, Zhang Y. What is the relationship between the "Fujisawa point" and postoperative knee valgus angle? A theoretical, computer-based study. Knee 2020; 27:183-191.

19. Bacon K, LaValley MP, Jafarzadeh SR, Felson D. Does cartilage loss cause pain in osteoarthritis and if so, how much? Ann Rheum Dis 2020; 79:1105-1110.

20. Vanhoenacker FM, Vertraete KL. Magnetic Resonance Imaging. In: Cassar-Pullino VN, Davies AM. Measurements in Musculoskeletal Radiology. Berlin: Springer; 2020:55-74.

21. Palmer AJR, Jones SG, Amiras D. Imaging Assessment of the Knee. In: Rodríguez Merchán, Liddle AD. Joint Preservation in the Adult Knee. Cham: Springer; 2017:13-21.

22. Kijowski R, Demehri S, Roemer F, Guermazi A. Osteoarthritis year in review 2019: imaging. Osteoarthritis Cartilage 2020;28:285-295.

23. Mezlini-Gharsallah H, Youssef R, Uk S, Laredo JD, Chappard C. Three-dimensional mapping of the joint space for the diagnosis of knee osteoarthritis based on high resolution computed tomography: Comparison with radiographic, Outerbridge, and meniscal classifications. J Orthop Res 2018;36:2380-2391.

24. Primorac D, Molnar V, Rod E, Jelec Ž, Cukelj F, Matišic V, et al. Knee Osteoarthritis: A Review of Pathogenesis and StateOf-The-Art Non-Operative Therapeutic Considerations. Genes (Basel) 2020;11:854.

25. Zhang Y, Chen X, Tong Y, Luo J, Bi Q. Development and Prospect of Intra-Articular Injection in the Treatment of Osteoarthritis: A Review. J Pain Res 2020;13:1941-1955.

26. DeRogatis M, Anis HK, Sodhi N, Ehiorobo JO, Chughtai M, Bhave A, et al. Non-operative treatment options for knee osteoarthritis. Ann Transl Med 2019;7:S245.

27. Petersen W, Ellermann A, Henning J, Nehrer S, Rembitzki IV, Fritz J, et al. Non-operative treatment of unicompartmental osteoarthritis of the knee: a prospective randomized trial with two different braces-ankle-foot orthosis versus knee unloader brace. Arch Orthop Trauma Surg 2019;139:155-166.

28. Cerciello S, Corona K, Neyret P. Lateral opening wedge distal femoral osteotomy. In: Oussedik S, Lustig S. Osteotomy about the knee. Cham: Springer; 2020:149-160.

29. Koh YG, Nam JH, Chung HS, Lee HY, Kang KT. Morphologic difference and size mismatch in the medial and lateral tibial condyles exist with respect to gender for unicompartmental knee arthroplasty in the Korean population. Knee Surg Sports Traumatol Arthrosc 2020; 28:1789-1796.

30. Dickschas J, Staubli A, Harrer J. Osteotomies around the Knee. Z Orthop Unfall 2019; 157:203-218.

31. Feldman A, Gonzalez-Lomas G, Swensen SJ, Kaplan DJ. Osteotomies about the knee. In: Scott WN. Insall \& Scott Surgery of the Knee. 6 th ed. Philadelphia: Elsevier; 2018:13231342.

32. Murata S, Saito H, Saito K, Yamamura T, Miyakoshi N, Shimada Y. Successful treatment of valgus knee osteoarthritis involving external tibial torsion with a double level osteotomy: a case report. Int J Surg Case Rep 2020; 77:510-514.

33. Pilone C, Rosso F, Cottino U, Rossi R, Bonasia DE. Lateral opening wedge distal femoral osteotomy for lateral compartment arthrosis/overload. Clin Sports Med 2019; 38:351-358.

34. Archbold P, Favarro LN, Prado RK, Magnussen R, Neyret P, Butcher C. Arthroscopy of the knee. In: Neyret P, Butcher C, Demey G. Surgery of the knee. 2 nd ed. Cham: Springer; 2020:5-16. 
35. Litchfield R, Amendola A. Proximal Tibia and Distal femoral Osteotomy. In: Sgaglione NA, Lubowitz JH, Provencher MT. The Knee: AANA Advanced Arthroscopic Surgical Techniques. Thorofare: Slack Inc; 2016: 297-311.

36. Sybrowsky C, Amendola A. Complex Approaches to the Diffuse Arthritic Knee: Including Corrective Osteotomy and Prothetic Resurfacing. In: Johnson DH. Operative Arthroscopy. 4 th ed. Philadelphia: Wolters Kluwer; 2013:754-767.

37. Burger JA, Kleeblad LJ, Sierevelt IN, Horstmann WG, van Geenen RCI, van Steenbergen LN, et al. A Comprehensive evaluation of lateral unicompartmental knee arthroplasty short to mid-term survivorship, and the effect of patient and implant characteristics: an analysis of data from the Dutch arthroplasty register. J Arthroplasty 2020; 35:1813-1818.

38. Kim KT, Lee S, Kim J, Kim JW, Kang MS. Clinical results of lateral unicompartmental knee arthroplasty: minimum 2-year follow-up. Clin Orthop Surg 2016; 8:386-392.

39. Rodriguez Merchán EC, Gómez Cordero P, Enciinas Ullán CA. Unicompartimental Knee Osteoarthritis: Unicompartimental Knee Arthroplasty. In: Rodriguez Merchán EC, Gómez Cordero P. Comprehensive Treatment of Knee Osteoarthritis. Cham: Springer; 2020:77-95.
40. Lustig S, Daher A, Magnussen R, Neyret P, Butcher C. Unicompartimental Knee Arthroplasty. In: Neyret P, Butcher C, Demey G. Surgery of the Knee. 2 nd ed. Cham: Springer; 2020: 205-217.

41. Li H, Ponzio DY, Ong A, Wei W, Wang B, Li Z, et al. Total knee arthroplasty for fixed valgus deformity correction using a modified lateral parapatellar approach. J Knee Surg 2020; 33:372-377.

42. Wang B, Xing D, Li JJ, Zhu Y, Dong S, Zhao B. Lateral or medial approach for valgus knee in total knee arthroplasty which one is better? A systematic review. J Int Med Res 2019; 47:5400-5413.

43. Greenberg A, Kandel L, Liebergall M, Mattan Y, Rivkin G. Total knee arthroplasty for valgus deformity via a lateral approach: clinical results, comparison to medial approach, and review of recent literature. J Arthroplasty 2020; 35:2076-2086.

44. Lee SS, Kwon KB, Lee YI, Moon YW. Navigation-assisted total knee arthroplasty for a valgus knee improves limb and femoral component alignment. Orthopedics 2019; 42:e253e259.

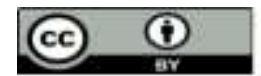

This work is licensed under Creative Commons Attribution 4.0 License

To Submit Your Article Click Here: Submit Manuscript
Ready to submit your research? Choose Auctores and benefit from:

$>$ fast, convenient online submission

$>$ rigorous peer review by experienced research in your field

$>$ rapid publication on acceptance

$>$ authors retain copyrights

$>$ unique DOI for all articles

$>$ immediate, unrestricted online access

At Auctores, research is always in progress.

Learn more https://auctoresonline.org/journals/clinical-orthopaedics-andtrauma-care- 